\title{
SOBRE A JUSTIÇA NO HORIZONTE DA PHRONESIS: LEITURAS DA ÉTICA A
} NICÔMACO DE ARISTÓTELES

\section{Leandro José de Souza Martins ${ }^{1}$}

Resumo: Este texto visa recordar as principais lições de uma ética da excelência centralizada na Justiça, conforme apresentada na Ética a Nicômaco de Aristóteles. A reflexão quer enxergar a noção de justiça como prática da sensatez humana (phronesis). A sensatez é a operação própria da alma humana, condição fundamental para toda ação que se quer para o bem (enquanto telos). Pela sensatez, o humano, dispõe-se a refletir sobre sua maneira de ser e agir e, dentro daquilo que se coloca como justo, abre-se na perspectiva de pensar melhor sobre si, sua ação e seus fins, superando os limites de uma situação particular (práxis). A razão se encontra pelo fato de cada homem poder se dispor ao alcance dos melhores fins (eudaimonia), e, ao mesmo tempo, reconhecendo-se como limitado, procura superar tal condição pela vida em comunidade (politiké). Poder compreender-se de antemão como restrito, mas, ao mesmo tempo, como alguém destinado à comunhão com outros, torna o homem propenso ao exercício do justo, visto a partir e para a concreção da sensatez.

Palavras-Chave: Ética; Justiça; Sensatez; Finalidade, Política.

\section{ABOUT JUSTICE ON HORIZON OF PHRONESIS: LECTURES OF ARISTOTLE'S NICOMACHEAN ETHICS}

\begin{abstract}
This paper aims to recall the main lessons of an ethics of excellence centered on Justice, as presented in Aristotle's Nicomachean Ethics. The reflection seeks to see the notion of justice as a practice of human sensibility (phronesis). Practical wisdow is the proper operation of the human soul, a fundamental condition for every action one wants for good (as telos). By reason, the human, is willing to reflect on his way of being and to act and, within what is presented as fair, opens up in the perspective of thinking better about himself, his action and his ends, surpassing the limits of a particular situation (práxis). The reason lies in the fact that every man can dispose himself to the best ends (eudaimonia), and at the same time, recognizing himself as limited, seeks to overcome this condition by living in community (politiké). Being able to understand himself in advance as restricted, but at the same time, as one destined to communion with others, makes the home prone to the exercise of the just, seen from and for the realization of practical wisdow.
\end{abstract}

Keywords: Ethics; Justice; Practical Wisdow; The End; Politics.

\footnotetext{
${ }^{1}$ Mestre em Filosofia pela UFOP; Bacharel em Direito pela FDCL. Professor EBTT de Filosofia, Sociologia e Introdução ao Direito no Instituto Federal de Minas Gerais (IFMG), Campus Ouro Branco. Endereço eletrônico: leandro.martins@ifmg.edu.br. Lattes: http://lattes.cnpq.br/8239895889023815.
} 


\section{INTRODUÇÃO}

Uma das grandes motivações do Estagirita na Ética a Nicômaco (E.N.), é descobrir qual o bem que o ser humano busca para sua realização. Aristóteles sustenta que qualquer ação humana, e, por conseguinte, toda pessoa, tem ou deveria possuir um fim a ser alcançado em sua vida. Portanto, todo o indivíduo, assim como toda ação e toda escolha, tem em mira um bem e este bem é aquilo a que todas as coisas tendem.

As hipóteses encontradas na ética aristotélica indicam a vida boa como vivência das excelências, junto com os outros, e que essa vivência é a felicidade, fruto de uma vida exercida com sensatez e com temperança. Entender, ainda que minimante, o significado de ética na perspectiva de um télos, é pressuposto fundamental para contemplar o raciocínio aristotélico.

Tal pensamento ético-teleológico de Aristóteles está exposto mais detalhadamente em três obras: Ética a Nicômaco, Ética a Eudemo e a Grande Ética. A ética, nas obras Aristotélicas, é considerada como uma parte ou um capítulo da política, que antecede a própria política. Ela diz respeito ao indivíduo, enquanto a política considera o homem na sua dimensão social. E o que os três livros têm em comum é justamente a compreensão de ética não em perspectiva idealista ou abstrata, mas como um enfrentamento das realidades concretas da existência e do agir humano. Nas palavras de Wolff, "Aristóteles escreve uma ética no sentido de uma doutrina do bem viver" (WOLF, 2010, p.11).

Das excelências éticas, aquelas que se baseiam na ação, a justiça é considerada a mais plena. A justiça configura o exercício de todas as virtudes, observando-se a instância da alteridade. Nas relações com os semelhantes, apresenta-se como a mais importante de todas: nem a estrela matutina ou estrela d'alva é tão maravilhosa (E.N. V, 1130a). Possuí-la é ser virtuoso, não apenas em si mesmo, mas com relação aos outros.

Por esse motivo, é ela, dentre todas as virtudes, a única que se reduz ao bem de outrem. De fato, ao se tornar justo, o indivíduo não o faz apenas na relação consigo mesmo (o que não existe para Aristóteles), mas sempre em comunhão com outro. Não se torna justo de modo individual, sem que, concomitantemente, torne justo o ambiente no qual se encontra, e as pessoas com quem se trava uma relação. A justiça não é um merecimento pessoal, a não ser que se entenda esse pessoal na relação intersubjetiva exigida pela própria eticidade.

Rev. de Argumentação e Hermeneutica Jurídica | e-ISSN: 2526-0103 | Porto Alegre | v. 4 | n. 2 | p. 118 - 138 | Jul/Dez. 2018 
Daí ser possível uma analogia ou uma conexão (cf. AUBENQUE,2008, p.102ss) entre uma excelência ética (a justiça), com uma das mais importantes excelências dianoéticas: a prudência, ou, conforme escolhido para figurar neste texto, phronesis. Em uma apertada síntese, pode-se afirmar que a phronesis é a capacidade de agir bem, mediante a virtude, nas relações mais particulares e contingentes da vida. A phronesis, dessa forma, é um tipo de percepção, de compreensão dos elementos do quotidiano, "que não tem sentido de uma intuição ética específica, mas que concebe a adequação da ação à situação e como uma contribuição para a realização do eidos humano" (WOLF, 2010, p. 166).

Identificadas no horizonte da phronesis, as dificuldades relativas ao agir e ser justo começam a diminuir. Afinal, conforme Aristóteles, a phronesis é a maneira de se conduzir sem abalos e dificuldades no processo da vida, agindo prudente e racionalmente em toda circunstância. A phronesis, muito mais conhecimento ou uma arte, é um modo de ser, uma capacidade para agir segundo uma disposição de caráter que discerne o que é bom e apropriado para um bem agir e um bom viver.

O método utilizado para a realização do trabalho foi descritivo-analítico com a abordagem de categorias consideradas fundamentais para o desenvolvimento do tema. $\mathrm{O}$ arcabouço teórico foi tomado na releitura de textos de Aristóteles, especialmente os livros I, II, III, V e VI da Ética a Nicômaco, citada, no texto como E.N.. A sequência do trabalho acompanha de perto a temática de cada livro, passando, em um primeiro momento, pela etimologia e sentidos da ética em Aristóteles. Em seguida, procura-se entender porque a ética pertence ao conjunto da ciência prática, compreendendo o que vem a ser, nesse particular, práxis.

No terceiro ponto, a preocupação fundamental foi citar os elementos constitutivos do ato ético em Aristóteles, levando à compreensão do conceito excelência, tradicionalmente traduzido por "virtude". De todas as virtudes consideradas éticas, a justiça é a maior. O texto, em seu quarto ponto, trabalha a noção de justiça, sem entrar em todos os detalhes que o Livro V da Ética a Nicômaco traz, uma vez que não seria aqui apropriado.

Por fim, destaca-se o que é a phronesis no pensamento aristotélico e, à guisa de conclusão, tentou-se oferecer uma ligação desses dois conceitos, salvaguardo, entretanto, as diferenças lógicas e conceituais entre essas excelências já apontadas desde o texto aristotélico.

Os procedimentos técnicos utilizados na pesquisa para coleta de dados foram a pesquisa bibliográfica e os grandes autores clássicos que pesquisam sobre a ética aristotélica,

Rev. de Argumentação e Hermeneutica Jurídica | e-ISSN: 2526-0103 | Porto Alegre | v. 4 | n. 2 | p. 118 - 138 | Jul/Dez. 2018 
tanto nacionais como estrangeiros. De tudo, preferencialmente foram as passagens do texto aristotélico as preferidas, aqui citadas conforme a edição e numeração crítica de Bywater.

A Ética à Nicômaco, considerado um escrito de Aristóteles maduro, com o seu sistema filosófico próprio e definitivo, foi aqui utilizada na versão portuguesa de António de Castro Caeiro. Tal tradução possui um grande referencial teórico que justifica a tradução de termos gregos um pouco diferente dos já tradicionais. Este trabalho segue a tradução do Prof. Caeiro, citando, em diversos momentos, sua justificativa linguístico-filosófica quanto à tradução do texto grego.

\section{I. ÉTICA E TELEOLOGIA: CONCEITUAÇÕES EM ARISTÓTELES}

Etimologicamente, a palavra é grega: ethos, tanto na sua grafia com eta, quanto na sua grafia com épsilon. Com eta, significa caverna (mais tarde, evolui para morada). Em grego, o termo remonta à época dos pastores nômades: estes, olhavam os costumes dos lobos que, mesmo sendo ferozes, nas suas cavernas, não brigavam entre si. Logo, o termo ethos refere-se a este local comum, uma morada, na qual existem certos comportamentos que objetivam o cuidado e o bem-estar de todos que ali habitam.

O sentido de morada é grande metáfora para os gregos na compreensão dos princípios inspiradores para a vida em comum, na qual, todos buscam o bem comum. Ethos assim, passa a ser o conceito que define o conjunto ordenado dos princípios, valores e motivações últimas das práticas humanas, pessoais e sociais, bem como o caráter, o modo de ser de uma pessoa ou de uma comunidade.

Em Aristóteles, entende-se por ética uma "teoria do agir correto e do bom caráter" (WOLF, 2010, p.20). Refere-se, assim, a todo agir humano, ao viver bem em todas as perspectivas. Em relação ao agir humano, este deve ser pautado na capacidade de escolher meios e fins que alcancem o objetivo maior, o fim/bem do próprio agir que, na perspectiva aristotélica, desemboca na eudaimonia, o melhor de todos os bens/fins.

Em outros termos, toda ação humana se dirige a um objetivo, um fim (1094a1). Há fins/bens superiores e inferiores, diversificados como a ação humana, mas há um Fim buscado por si próprio. Este bem supremo é obtido pela Perícia Política, cujo télos é o Bem humano identificado como Felicidade (eudaimonia), entendida, por sua vez, como viver bem e agir

Rev. de Argumentação e Hermeneutica Jurídica | e-ISSN: 2526-0103 | Porto Alegre | v. 4 | n. 2 | p. 118 - 138 | Jul/Dez. 2018 
bem (1094a/1095a). A felicidade é o supremo bem alcançado pela ação humana; é o fim mais importante de toda ação (1094a30); é certa atividade da alma segundo uma excelência (areté), é agir de forma excelente (1102a6).

Segundo Wolff, Aristóteles usa o termo fim tanto quanto objetivo, escopo, quanto para indicar o significado de "Bem", presente nas primeiras linhas da E.N. Nas palavras da autora:

Na primeira frase fala-se de agathon ti, que se pode traduzir por "certo bem" ou significando mais ou menos o mesmo, - "um bem". Quando, logo a seguir, Aristóteles adota a palavra "bem" por "fim", significa então que a expressão "um bem" deveria indicar o fim de cada ação ou o objeto de uma aspiração, Correspondentemente a segunda frase deveria resumir lapidarmente a definição da palavra "bem", afirmando que o bem é o fim de toda aspiração (WOLF, 2010, p.23).

Assim, télos significa, dentre tantas coisas, a dação de sentido à ação humana, um objetivo que torna a vida capaz de ser pensada e exercida segundo os ditames da razão e mediante certos princípios fundamentais. Nas primeiras linhas da E.N., Aristóteles ressalta a relação entre fim e bem. Justamente porque, na concepção grega de fim, à qual Aristóteles se fia, o bem é entendido como o apropriado, o devido, correspondente. E fim, télos, significa completude de uma execução, acabamento de um agir, cumprimento de uma missão.

\section{DA METODOLOGIA DO AGIR/SABER ÉTICOS: TÉLOS E PRÁXIS}

Há, segundo Aristóteles, um fim superior. Este é o bem supremo é obtido pela Perícia Política e cujo télos é o Bem humano identificado como Felicidade (eudaimonia).

Parece, contudo, haver uma opinião formada de que terá que dizer respeito à mais autêntica de todas as ciências e àquela que melhor é capaz de projetar a partir de princípios fundamentais. Tal parece ser a perícia política, porquanto é ela mesma que determina quais são as ciências necessárias aos Estados e quais são aquelas que cada classe de cidadãos deve aprender, e até que ponto. Vemos até que aquelas atividades que alcançam um maior prestígio, como a estratégia, a economia e a retórica, estão sob a sua alçada. Mas a perícia política não faz uso das restantes outras perícias que dizem respeito à ação, ela legisla a respeito do que deve ser e de que coisas se têm de evitar. O fim que ela persegue envolve de tal modo os fins das restantes, ao ponto de tratar-se do bem humano (E.N., I, 1094b).

O alcance dos fins passa por uma metodologia rigorosa, em Aristóteles.

Corresponde, como dirá o Peripatético, ao modo mais dedicado e sério que se conduz a ação

Rev. de Argumentação e Hermeneutica Jurídica | e-ISSN: 2526-0103 | Porto Alegre | v. 4 | n. 2 | p. 118 - 138 | Jul/Dez. 2018 
humana, especialmente àquela que diz respeito ao próprio bem de quem age, ao que dá sentido à vida e à pessoa completamente. Seria por demais importante reconhecer esse fim: o mais importante, aquele que corresponde ao específico do ser humano, é o previsto pela ética, que se faz muito mais como escolhas corretas ante questionamentos corretos, do que mero conjunto de princípios vazios e sem ligação com a realidade.

Segundo Lima Vaz (2002, p. 114ss), Aristóteles se preocupa por demais com o método de estudo, cuja aplicação precisa contemplar a divisão de saberes estabelecida na Metafísica. De fato, Aristóteles compreende os saberes enquanto teórico (teorético), prático e poiético. Seria o saber teórico aquele cujo fim é a última verdade das coisas. Nesse saber, há a obediência à necessidade do inteligível, da razão, do logos. Formam, portanto, o conjunto de ciências contemplativas e, pela mesma razão terminológica, teoréticas (teoria).

Por sua vez, as ciências poiéticas são aqueles que determinam a confecção (poiésis) de um objeto externo. Ou seja, é o resultado de uma ação, de uma produção. Conforme Ferrater Mora (2001, p. 2305), o verbo poieoo significa, “originalmente, 'fazer', 'fabricar', 'produzir'. Neste sentido, poder-se-ia usar o termo 'poética' para designar a doutrina relativa a todo fazer".

$\mathrm{Na}$ theoria, compreende-se a ciência enquanto contemplação do verdadeiro (portanto, algo inteligível, conceitual, no uso puro da razão intelectiva). Quanto a poíesis, importa a fabricação de um objeto, que denota algo extraordinariamente concreto, tangível. Entretanto, algo comum liga as ciências teóricas e poiéticas: o fim de ambas é a perfeição do objeto. Pe. Vaz explica: "Nas ciências teoréticas e poiéticas, o fim é a perfeição do objeto: ou a ser contemplado em sua verdade na teoria, ou a ser fabricado em sua utilidade na poiesis". (LIMA VAZ, 2002, p.116, grifos do original).

O fim comum entre theoría e poíesis releva a distinção destas com o conhecimento prático, cujo fim "é a perfeição do agente pelo conhecimento da natureza e das condições que tornam melhor ou excelente o seu agir (práxis)" (LIMA VAZ, 2002, p. 117). Dentro desta forma de conhecimento está o pensamento ético de Aristóteles e, por conseguinte, toda sua reflexão sobre a Justiça e demais excelências (aretai) humanas, conforme a natureza específica da alma humana e cujo télos é a eudaimonia ${ }^{2}$ supremo bem alcançado pela ação humana, fim mais importante de toda ação (ARISTÓTELES, E.N., 1094a30; 1102a6).

\footnotetext{
${ }^{2}$ Para Aristóteles, a eudaimonia (felicidade), é uma certa atividade da alma de acordo com uma excelência completa, uma excelência humana não do corpo, mas da alma. (E.N.,1102a). Literalmente, eudaimonia significa
} 
A felicidade é entendida, neste contexto, como viver bem e agir bem (1094a/1095a). A felicidade é o supremo bem alcançado pela ação humana, é o fim mais importante de toda ação (1094a30). É certa atividade da alma segundo uma excelência (areté), é agir de forma excelente (1102a6). A felicidade consiste em um bem supremo, a partir de uma disposição eletiva da alma de acordo com a virtude. "A posse da virtude em sua integralidade, aliada à sua práxis, confere ao sujeito que a possui um gozo que, além de não-efêmero, é usufruído independentemente de qualquer coisa” (BITTAR, 2003, p. 1014). Conforme orienta Reale:

O bem do homem só poderá consistir na obra que lhe é peculiar, isto é, na obra que ele e só ele pode realizar, assim como, em geral, o bem de cada coisa consiste na obra que é peculiar a cada coisa. A obra do olho é ver, a obra do ouvido é ouvir, e assim por diante. E a obra do homem? a) Esta não pode ser o simples viver, dado que o viver é próprio de todos os seres vegetativos. b) E não pode ser também o sentir, dado que este é comum também aos animais. c) Resta, pois, que a obra peculiar do homem seja a razão e a atividade da alma segundo a razão. O verdadeiro bem do homem consiste nessa obra ou atividade de razão, e, mais precisamente, no perfeito desenvolvimento e atuação dessa atividade. Esta é, pois, a "virtude" do homem e aqui deve ser buscada a felicidade (REALE, 2012, p. 114).

Retornando ao conceito de práxis, esta se relaciona a todas as ações humanas, e são as formas de relacionamento ético que o humano é capaz de estabelecer em sociedade. Etimologicamente, o termo práxis parece proveniente do verbo prassoo, prassein/prattein, atravessar. Seria, portanto, a ação de atravessar, conforme Liddle e Scott. Este atravessar lembra o percurso singrado por um barco, ou uma jornada feita por um viajante. Constitui, portanto, todas as experiências, modificações, aprofundamentos vividos e que fazem alguém ou algo ser diferente após esse exercício.

Conforme Aristóteles, não é um conhecimento teórico nem algo que se produz fora do indivíduo, mas algo que o constitui internamente, que provoca nele novos modos de interação e interpretação, uma nova dação de significados às coisas. "Práxis é a ação de atravessar, enquanto nomen actionis, isto é, aquilo por que se passou, os momentos bons e maus que atravessaram, as circunstâncias concretas de cada vez que se constituem" (CAEIRO, 2009, p. 248).

O sentido original do substantivo "práxis" é dificilmente vertido para português através de termos como "ação" ou "prática". O verbo "prattein" significa passar por, atravessar. Significa também estar sujeito ao acaso, ao feliz, tanto quanto ao infeliz. Significa bem assim "levar a cabo", "realizar", "cumprir". Nesta conformidade, o horizonte prático é o espaço onde tem lugar aquilo por que se passa: as situações em que caímos e as situações que criamos (CAEIRO, 2009, p. XI).

\footnotetext{
"bom espírito" ou, como escreve Lima Vaz, "proteção de um bom daimon". Para este autor, "significa a excelência ou perfeição resultante no agente da posse do bem ou bens que nele realizam melhor sua capacidade de ser bom (LIMA VAZ, 2002, p. 118-119, grifos do original).
}

Rev. de Argumentação e Hermeneutica Jurídica | e-ISSN: 2526-0103 | Porto Alegre | v. 4 | n. 2 | p. 118 - 138 | Jul/Dez. 2018 
Com efeito, a ética é muito mais saber postar-se num movimento de escolha e deliberação ante as várias possibilidades que a vida oferece. E, segundo a ética, qualquer pessoa deveria deter-se ante estas questões, deixar-se mover por um coletivo de inquietações para que possa, racional e livremente, estabelecer alguma motivação superior pela qual viver e para a qual se dirige. A conduta da vida, o propósito de uma existência seria muito mais fácil de ser identificado se se entendesse a ética não como um conjunto de respostas, mas como o desafio da escolha e da finalidade defronte às inúmeras possibilidades do existir.

\footnotetext{
A ética (...) é a ciência da praxis, que significa ação, cujo objeto é a ação individual e inter-individual, ciência que, necessariamente por assim dizer, como o rio que espraia suas águas no mar, encerra-se no bojo de uma ciência prática mais ampla, ou seja, a política, o ser humano (anthropos), na sua [ti esti], se manifestando como animal político, ou mais precisamente animal da polis, Estado (BINI, 2014, p. 7)
}

\section{DOS ELEMENTOS CONSTITUTIVOS DA ÉTICA EM ARISTÓTELES}

As mais fundamentais questões trazidas pela ética referem-se tanto a problemas pessoais e particulares, quanto à economia social e a política comunitária. Provocam no sentido de questionar o quão responsável é alguém no planejamento de sua vida, na avaliação de sua conduta e que bem (bens) consegue legar.

Enquanto investigação daquilo que é próprio do ser humano, na E.N., Aristóteles elabora uma distinção de "tipos de vida". Nessa teoria, rejeita tanto uma vida que consiste na nutrição e no crescimento, quanto uma vida apenas mediada pelos sentidos. Aquela, é comum aos vegetais; esta, comum a qualquer animal. O que é próprio do ser humano é um tipo de vida ativa, uma função, conforme expressa o termo ergon do texto. Uma vida, portanto, que, é contemplativa em ação, desenvolvida mediante um severo processo de habituação (hexis), ou como um modo de ser que, adquirido por disposição e hábito, é usufruído permanentemente por um indivíduo.

Hexis, portanto, é um habitus, um modo de agir constante e deliberado. Atente-se para o fato de ser uma ação, não só um desejar. Tal agir advém de uma metodologia educativa exigente, cujo processo requer, sobretudo, experiência de vida e conhecimento dos princípios fundamentais. Com efeito, a investigação ética e a perícia política pressupõem não um saber 
teórico, mas um agir, e o conhecimento só produz efeito sobre aqueles que agem conforme um princípio racional (1095a), adquirido mediante processos corretos de habituação (1095b).

A reflexão aristotélica quanto à ética compreende duas categorias de excelências: as morais, fundamentadas na vontade, e as intelectuais, baseadas na razão. O objetivo da ação moral é a justiça, assim como, a verdade é o objetivo da ação intelectual. O resultado da ação é muito importante na ética aristotélica, a ponto de ser classificada como Ética Teleológica. Mas, este resultado que se quis alcançar não é obtido de qualquer modo. Na intenção de fortalecer a cultura grega, Aristóteles indica que o último fim é a felicidade, isto é, o bem em si definido como aquilo a que tendem todas as coisas. (E.N. I, 1094a18-2).

O critério da moralidade para Aristóteles é o justo meio ${ }^{3}$ para alcançar um fim racionalmente. O justo meio é o critério para saber o que é a excelência, aprendida pelo hábito, de se treinar na intenção de fazer o Bem, bem para todos. O justo meio é o que está entre dois extremos e permite a cada pessoa conhecer suas faculdades, harmonizar equilibradamente suas paixões, de forma que estas sejam guiadas pela razão na disposição de caráter. Aliás, o que faz o homem ser virtuoso é a disposição de seu caráter, quando no uso de suas capacidades, equilibra suas paixões e encontra seu Justo meio (E.N. I, 1094 a; 1095a1095b 24-26).

A partir do diapasão da finalidade de cada coisa, a ética, e, especialmente, a ética aristotélica, não apenas diz respeito à maneira como os indivíduos devem tratar uns aos outros, nem só como devem se comportar em sociedade. Elas também dizem respeito a como a lei deve ser; quais valores identificam um conjunto social; quais mecanismos são legítimos e moralmente aceitáveis para que uma sociedade venha a se organizar. São questões sobre justiça, sobretudo. Questões que levam à eleição de valores e excelências que fazem cada pessoa alcançar sua completude.

Com efeito, toda a ideia aristotélica sobre a justiça, a partir desse contexto ético na qual se desenvolve e vista como a maior de todas as excelências, circunscreve-se em um pensamento moral com ecos em uma autêntica Filosofia do Direito e em qualquer consideração sobre a justiça que se queira fazer academicamente séria. Muito mais que Platão, há em Aristóteles um maior cuidado e refinamento do vocabulário conceitual e instrumental

\footnotetext{
${ }^{3} \mathrm{O}$ justo meio se define na relação equilibrada entre dois polos, uma igualdade, seja ela proporcional ou absoluta. Esse equilíbrio reside no fato de ambos compartilharem de um meio, não se invadindo o campo do que é devido ao outro, observando, entretanto, as tendências que cada parte possui.
}

Rev. de Argumentação e Hermeneutica Jurídica | e-ISSN: 2526-0103 | Porto Alegre | v. 4 | n. 2 | p. 118 - 138 | Jul/Dez. 2018 
sobre a doutrina da justiça enquanto excelência ética, justificados, especialmente, pela orientação teleológica e eudaimonística de sua filosofia.

Necessária se faz a compreensão da justiça em Aristóteles no horizonte de um agir racional e ordenado, correspondente à natureza primeira do humano. A ética e a perícia política são, na E.N., uma investigação daquilo é próprio ao ser humano (1097b), e, de todos os modos excelentes de vida, o modo justo é o principal. Determinar o modo justo só se faz possível quando se tem claras tanto as motivações quanto à finalidade de um agir, não de um pensar. E tal agir não procura apenas o bem-estar pessoal: a justiça, excelência completa, dirige-se a um fim supremo, identificado como a vida em comunhão com outros. Nas palavras de Aristóteles:

\begin{abstract}
Mesmo que haja um único bem para cada indivíduo em particular e para todos em um geral num Estado, parece que obter e conservar o bem pertencente a um Estado é obter um bem maior e mais completo. O bem que cada um obtém e conserva para si é suficiente para se dar a si próprio por satisfeito; mas o bem que um povo e o Estado obtêm e conservam é mais belo e mais próximo do que é divino (E.N. I, 1094b7-12).
\end{abstract}

\title{
IV. A EXCELÊNCIA DA JUSTIÇA E SEUS COROLÁRIOS
}

A Justiça sempre foi objeto de estudos das mais diversas correntes de pensamento da humanidade. Aristóteles, como seu mestre Platão, entende a Justiça como a virtude total, a predisposição que o indivíduo tem para ser ou não justo, ao mesmo tempo. Assim, dá Aristóteles sua primeira definição de Justiça, que se estabelece tanto como uma operação espiritual quanto uma operação concreta na vida das relações. Em suas palavras, uma “disposição de caráter que torna as pessoas propensas a fazer o que é justo, que as faz agir justamente e a desejar o que é justo".

O próprio Aristóteles tomou o termo diké para uma análise etimológica, dando ao mesmo o sentido de dividir ao meio (1132a), originando uma igualdade entre as partes. Conforme se lê na E.N., ainda que haja certa ambiguidade no termo justiça (1129a), bem como no termo injustiça, a função do juiz (dikasthes) seria justamente restabelecer a igualdade, tornando o mesmo, uma personificação viva da justiça. Ao lado deste termo, mas não sendo seu sinônimo, há o termo nomothetes, ou seja, o legislador, com a função muito mais de criação das leis, do que de sua execução (E.N., V, 1131a).

Rev. de Argumentação e Hermeneutica Jurídica | e-ISSN: 2526-0103 | Porto Alegre | v. 4 | n. 2 | p. 118 - 138 | Jul/Dez. 2018 
No livro V da E.N., Aristóteles disserta sobre a excelência da Justiça. Inicia dizendo que a justiça é uma disposição intermédia, um meio-termo entre extremos. (E.N., V, 1129a4), e conceitua como "disposição de caráter a partir da qual os homens agem justamente, ou seja, o fundamento das ações justas e o que os faz ansiar pelo que é justo". A justiça se reconhece tanto por sua prática, quanto por quem a pratica. E Aristóteles reitera que, antes de tudo, “justo será quem observa a lei e respeita a igualdade" e, por conseguinte, a "disposição justa é, então, por um lado, a observância da lei e o respeito pela igualdade” (E.N., V, 1129a36).

O justo e, consequentemente, a justiça, é um equilíbrio/limite (mesotes). Em outras palavras, a justiça é a capacidade de o indivíduo não se deixar levar por extremos, sejam eles excessos ou lacunas. Tal limite equilibrado é dado pela legislação, cuja finalidade não é outra senão procurar o interesse de todos prescrevendo como estes devem agir segundo as mais diversas excelências (E.N, V, 1129b19). Em suma, Aristóteles arremata dizendo que a justiça é "uma excelência completa, não de uma forma absoluta, mas na relação com outrem" (E.N., V, 1129b27). É justamente por tal relação que a Justiça, dentre todas as excelências, é a mais poderosa.

Aristóteles justifica:

(A Justiça) é completa porque quem a possuir tem o poder de a usar não apenas só para si, mas também com outrem (...) é a única das excelências que parece também ser um bem que pertence a outrem, porque, efetivamente, envolve uma relação com outrem, isto é, produz pela sua ação o que é de interesse para outrem, seja esse alguém um superior ou um igual (E.N., V, 1129b-1130a).

Conforme expressa Fassó, as primeiras afirmações de Aristóteles sobre a justiça acompanham a tradição grega, que também compreendia a justiça como virtude ética por excelência, compartilhando os sentidos de legitimidade ou igualdade. De fato, Aristóteles, quando afirma ser a lei a orientação do agir em comunidade, entende a justiça como legitimidade. E a igualdade corresponderia ao fato de a justiça estabelecer um equilíbrio nas relações entre coisas e pessoas. Por isso, a justiça é, em Aristóteles, uma excelência completa.

Entretanto, junto a esta justiça geral, deve-se considerar uma justiça como parte da excelência (E.N. V, 1130a). Aristóteles faz discernir que há uma justiça geral, a excelência completa, a disposição de caráter que faz agir em justiça e torna alguém justo, bem como há uma justiça particular, que ocorre na vida cotidiana e se desdobra na sociedade.

Estas relações são conjugadas pela Política, ciência de destaque para Aristóteles na determinação do que se passa na polis, sobretudo naquilo que compete alcançar, o bem 
comum: a eupraxia (boa ação a partir de um conjunto de valores partilhados e vividos por determinado grupo), a eupsiquia (valores sedimentados que formam a subjetividade), por fim, a eudaimonia. Portanto, cada ser racional deve ser capaz de conhecer-se e de se relacionar com os demais a partir das indicações da Política e da Ética, que possuem fím comum.

\begin{abstract}
À justiça propriamente dita, à justiça como virtus ad alterum, social, que Aristóteles se refere claramente no decorrer de sua obra, não é, decerto, a mesma sugerida por Platão, como virtude total, perfeição da alma (...) é, para ele, como se lê nos primeiros livros da Ética a Nicômaco, a disposição da alma, consistindo em observar o justo meio nos comportamentos opostos ao excesso ou ao defeito (FASSÓ, 1966, p. 62)
\end{abstract}

Universalmente aceita, e ainda influenciando a teria atual, Aristóteles apresenta o conceito de Justiça Particular. Ou seja, a justiça como parte da excelência, o que se refere ao outro singularmente no relacionamento direto entre as partes. A justiça particular pode ser entendida como uma disposição que na esfera dos bens exteriores, leva agir, justamente, segundo uma escolha deliberada.

São duas espécies de justiça particular. A espécie distributiva é virtude na distribuição das honras ou das riquezas ou de outras vantagens que devam ser repartidas entre os membros da comunidade (E.N., V, 1130b 33; 1131 a). Nesta, em suma, o que importa é o mérito das partes.

A outra espécie é a justiça comutativa ou corretiva, na proporcionalidade na repartição. O justo distributivo relaciona-se com todo tipo de distribuição levada a efeito na pólis, seja de dinheiro, seja de honras, cargos ou quaisquer outros bens passíveis de serem participados aos governados. Quanto à justiça corretiva, é a que realiza a igualdade nas transações individuais, mas, diferentemente da distributiva, não leva em conta os sujeitos da relação igualitária, mas sim as coisas que devem ser igualadas.

Ao lado de tais afirmações, Aristóteles evidencia a virtude prudencial de eleição de fins e meios individuais que correspondam ao bem do todo: a phronesis. Esta virtude, tão importante no pensamento ético aristotélico, dá consistência ao processo de escolha (diairesis) e de deliberação (boulesis ${ }^{4}$ ), momentos prévios e garantes do ato moral, tanto da parte do indivíduo para consigo mesmo, seja deste para o todo social no qual está inserido. Se a diairesis elege fins atingíveis ou não pelo movimento de desejo/vontade, a deliberação é a

\footnotetext{
${ }^{4}$ Etimologicamente, o termo indica a deliberação que realiza uma vontade, um desejo. Termo ético-político, vem da assembleia ou tribunal dos anciãos, no qual se decidia o destino e as orientações mais importantes para a Polis. (AUBENQUE, 2008, p. 110ss; PEREIRA, 1987, p. 275; LIDDELL; SCOTT, 1996).
} 
opção racional acerca de meios para a "atualização" destes fins concebidos pela vontade (BITTAR, 2003, p. 1036). O caráter "prudencial” da ação requer a necessidade de reformular constantemente a práxis 5 .

Outro aspecto relevante em Aristóteles é a sua consideração da justiça enquanto ação deliberada, "uma disposição em razão da qual o homem justo é definido como apto a executar, pela escolha deliberada, o que é justo" (E.N., V, 1134a). Sabe-se que a deliberação também é uma característica essencial da virtude em geral: “A virtude é uma disposição de agir de modo deliberado" (E.N., II,1107a). Nesse sentido, diz-se que o homem justo não é aquele que apenas cumpre ações justas, mas sim aquele que as executa voluntariamente ${ }^{6}$, o que se dá quando algo é executado sem coação ou sem ignorância. Entendida como hábito, apta se torna a justiça quando cada cidadão começa, em sua vida, a fazer o mesmo que os homens virtuosos de seu tempo.

Cada indivíduo é chamado a perceber o quanto lhe é verdadeiramente devido, sem incorrer na desmedida (Hybris), seja por excesso, seja por carência, promovendo, assim como Platão postulou, o bem da polis. Pois, é nela, que o ser humano se faz humano e racional, distinto de qualquer outra realidade encontrada no universo.

Apenas por meio da associação política, diz Aristóteles, podemos exercitar a
faculdade humana essencial da linguagem, porque somente em uma pólis
deliberamos com os demais sobre justiça e injustiça e sobre a natureza da vida boa.
"Vemos assim que a pólis existe por natureza e antecede o indivíduo", escreve ele
no Livro 1 de A Política. "Antecede", nesse caso, refere-se à função ou ao objetivo,
e não a algo cronologicamente anterior. Os indivíduos, as famílias e os clãs já
existiam antes das cidades; mas somente na pólis podemos realizar nossa natureza.
Não somos autossuficientes quando estamos isolados, porque não podemos
desenvolver nossa capacidade de linguagem e de deliberação moral (SANDEL,
2012, p. 243).

\footnotetext{
${ }^{5}$ se, pois, a prudência não é nem ciência nem arte, resta que seja uma disposição (o que a distingue da ciência) prática (o que a distingue da arte). Mas isso provaria, no máximo, que ela é uma virtude. Para distingui-las de outras virtudes morais, é preciso acrescentar outra diferença específica; enquanto a virtude moral é uma disposição (prática) que concerne a escolha, a prudência é uma disposição prática que concerne à regra da escolha. Não se trata de retidão na ação, mas de correção do critério, razão pelo qual a prudência prática acompanhada de uma regra verdadeira. Mas essa definição é ainda ampla demais, pois poderia ser aplicada a qualquer virtude intelectual: se distinguirá, então, a prudência dessa outra virtude intelectual, que é a sabedoria, precisando-lhe o domínio, que não é o Bem e o Mal em geral, ou o Bem e o Mal absolutos, mas o bem e o mal para o homem" (AUBENQUE, 2008, p. 61-62).

${ }^{6}$ Por voluntário, Aristóteles entende "tudo aquilo que, entre as coisas que estão no ser do agente, é executado com conhecimento de causa, isto é, sem ignorar nem a pessoa que sofre a ação, nem o instrumento empregado, nem o objetivo a atingir" E.N., V, 10, 1135a 24; III, 1, 1109b 35.
}

Rev. de Argumentação e Hermeneutica Jurídica | e-ISSN: 2526-0103 | Porto Alegre | v. 4 | n. 2 | p. 118 - 138 | Jul/Dez. 2018 
Mas, o Filósofo alerta que, não obstante parecer fácil, a prática da justiça pode ser um desafio ou até uma dificuldade. Afinal, segundo Aristóteles, cada indivíduo tem a possibilidade de praticar as ações justas, o que não significa que as praticará de fato. $\mathrm{O}$ que torna uma ação justa é realiza-la segundo a disposição de caráter. Não basta, portanto, agir justamente como que por acidente. Tampouco, saber o que é o justo e a excelência da justiça equivalem como agir, a que dirigir a ação ou com quem agir e, por fim, quando agir justamente (E.N., V, 1137a). Para tanto, a phronesis vem como subsídio autêntico, pois determinará, como excelência da razão, compreender de antemão e racionalmente, a situação contextual que exigirá o agir justo.

\section{A PHRONESIS, HORIZONTE DO AGIR E DA PLENITUDE DO HUMANO}

A partir de Aristóteles, a ação humana e tudo que dele deriva têm fundamental importância. Afinal, é nela e a partir dela que se pode falar ou dar a conhecer a realidade ética do comportamento humano, a definição daquilo que faz o humano ser o que ele é. O princípio da ação não é algo a ser obtido nem pela pura intelecção, tampouco como um produto externo e independente. Práxis é agir refletidamente, e o saber prático, ao qual Aristóteles chancela a excelência, é adquirido tão-somente quando se realiza, quando se pratica. Pouco adianta conhecer, saber ou detectar a excelência. Importa é viver de acordo com excelência, colocando-a como fim de toda ação, no mesmo momento que se põe a agir.

\footnotetext{
Tal como não se trata de uma diferença sem importância aquela que há entre o que existe como mera disposição e o que está em atividade. Na verdade, é possível que uma condição subsista sem que daí resulte qualquer bem, como acontece com que está a dormir ou com alguém que está, de algum outro modo, inativo; assim, não é capaz de entrar em atividade, coisa necessária à ação e a fortiori à boa ação. $\mathrm{O}$ mesmo acontece nas Olimpíadas. Não são coroados os mais admiráveis, nem os mais fortes, mas os que disputam a vitória (é entre estes que se contam os que obtém a vitória). Do mesmo modo são também os que agem corretamente durante toda a existência quem alcançam coisas belas e boas (E.N., I, 1099a, grifos nossos).
}

Em Aristóteles, a Práxis relaciona-se com a excelência, tradução aproximada do termo Areté, comumente traduzida por virtude, representa, em verdade, um agir de modo excelente, é a qualidade do que é melhor, superior. Não significa, portanto, apenas uma aptidão, mas um modo de ser, uma característica que releva quanto uma ação ou alguém faz da melhor maneira possível. Seria, portanto, como já escrito, uma excelência. 
Conforme escreve na Ética a Nicômaco, a excelência é um agir da melhor maneira, o exercício mais pleno do que é especificamente humano. Em outros termos, excelência não é um estado de espírito, mas uma maneira de ser. Não se fundamenta nem nos prazeres ou na fuga dos sofrimentos, tampouco se reduz às honrarias ou ao dinheiro. Agir na excelência é exercer funções correspondendo ao que se espera na vida em comunidade. Enfim, a excelência não é simplesmente uma sabedoria (como sustentava Sócrates), mas implica em um saber prático.

Como já delineado a excelência moral não é atributo natural do homem: em Aristóteles, ela é efeito de um exercício reiterado do ato, da prática constante e regular, enfim, de uma dinâmica de habituação. "A condição de nascer ser humano distingue o homem das demais espécies de seres animais. A natureza do homem torna-o capaz de modificar-se pelo hábito, tanto pelo caminho do bem, como para a senda do mal" (SILVA, 2003, p.53). Se, in natura, o ser humano não possui a excelência moral, ela a pode alcançar pela habituação e prática constante dos atos.

Aristóteles define a sabedoria prática, ou como mais bem traduzido (Cf. CAEIRO, 2009, p. 249), a sensatez (phronesis) como "um estado racional e verdadeiro de capacidade de agir em relação ao bem humano". E aquele que é investido desta sabedoria prática tem condições de elaborar uma concepção verdadeira do fim que lhe cabe de modo excelente, bem como possui, enquanto possibilidade, uma capacidade de planejamento e meios aptos para realização desse fim eficazmente. Pois, agindo de acordo com a phronesis, alguém se torna capaz de deliberar corretamente, tanto em relação ao fim, quanto aos meios adequados para alcançar aquele télos.

Parece ser sensato aquele que tem o poder de deliberar corretamente acerca das coisas que são boas e vantajosas para si próprio, não de um modo particular (...) Uma indicação disto é dada pelo fato de, ao falarmos daqueles que são sensatos, dizermos que são capazes de calcular de modo correto a forma de chegarem a obter um certo objetivo final sério, fim este que não se encontra entre os produtos de qualquer perícia (E.N. VI, 1140a24ss).

Em outros termos, a phronesis é o pensar as coisas que determinam a vida e levam a uma escolha, ante os desafios que a própria existência presume. Tais desafios são tanto os que ocorrem no mundo externo, quanto, sobretudo os que povoam a intimidade de cada pessoa e a faz agir e querer de modo tão diverso, e nem sempre correspondendo a gostos e escolhas mais estéticas. Ela é uma excelência da razão humana, e, portanto, preside à constituição do caráter de cada indivíduo, fazendo-o de acordo com a natureza de sua razão. A phronesis, é, por fim,

Rev. de Argumentação e Hermeneutica Jurídica | e-ISSN: 2526-0103 | Porto Alegre | v. 4 | n. 2 | p. 118 - 138 | Jul/Dez. 2018 
uma possibilidade de compreender antecipadamente para melhor agir em uma circunstância específica.

No campo do agir ético, especialmente, no agir justo, essa capacidade de prever e analisar de antemão é fundamental. Nada mais importante para a execução do justo o senso bem equilibrado que determina, do melhor modo possível, o fim mais desejado. Mas, muito mais que determinar resultados, pela phronesis cada indivíduo procura equilibrar suas tendências, inteligência e agir com as escorregadias e tantas vezes impetuosas situações do viver, mormente o viver em comunidade.

Conforme Aubenque:

\begin{abstract}
A prudência é uma disposição prática que concerne à regra da escolha. Não se trata da retidão da ação, mas da correção do critério, razão pela qual a prudência é uma disposição prática acompanhada de regra verdadeira. Mas essa definição é ainda ampla demais pois poderia ser aplicada a qualquer virtude intelectual: se distinguirá, então, a prudência dessa outra virtude intelectual, que é a sabedoria, precisando-lhe o domínio, que não é o Bem e o Mal em geral, ou o Bem ou o Mal absolutos, mas o bem o mal para o homem (2008, p. 62, grifos do original).
\end{abstract}

Interessa, ainda, dentro do conceito de prudência, o quanto essa virtude relaciona-se com algo existencial. De fato, Aristóteles não pensa a phronesis nos mesmos moldes das outras virtudes, já que, em relação à prudência, importa mais para Aristóteles pressupor em sua reflexão a existência do homem prudente, aquele que sabe o que é bom "para nós" e que se move no nível do particular. Conforme Aubenque (2008, p.84ss), o phronimos não é "um intérprete da reta regra, mas é a própria reta regra"; por ele, designa-se uma "qualidade intelectual", pois a phronesis é uma "virtude da inteligência e não do ethos"; por fim, o phronimos é alguém dotado de inteligência crítica, que julga com competência e propriedade, uma vez que se capacitou pela vivência de experiências concretas e na qual se fez enquanto prudente.

O prudente se vê reconhecido por um certo tipo de superioridade intelectual - seria necessário dizer, transcrevendo exatamente Aristóteles, teórico, lembrando que theôrein tem o sentido de ver, sem que essa visão seja necessariamente do tipo contemplativo. Que Aristóteles nos tenha prevenido, um pouco acima, que o objeto dessa capacidade não pode ser o necessário, mas o contingente, que esse saber não pode, pois, ser dito nem ciência nem mesmo arte, não muda em nada o fato da Aristóteles continuar a ver na virtude do político uma virtude intelectual (...) $\mathrm{O}$ prudente conhece o que é bom para ele próprio, no caso da prudência privada, e para os homens em geral, no caso da prudência política, o que é, por certo, uma particularização da ideia platônica de Bem, mas não uma particularização arbitrária,

Rev. de Argumentação e Hermeneutica Jurídica | e-ISSN: 2526-0103 | Porto Alegre | v. 4 | n. 2 | p. 118 - 138 | Jul/Dez. 2018 


\section{SOBRE A JUSTIÇA NO HORIZONTE DA PHRONESIS: LEITURAS DA ÉTICA A NICÔMACO DE ARISTÓTELES}

abandonada à concepção de cada um sobre o bem (...) O prudente não é, então, o puro empírico que vive o dia-a-dia sem princípios e sem perspectivas, mas é o homem de visão de conjunto (AUBENQUE, 2008, p.94-96).

A justiça, em Aristóteles, sem dúvida, é uma tarefa que realiza tanto pessoal quanto politicamente. Quem é justo faz justiça, torna justas as relações e sujeitos delas. Mas a justiça só vem mesmo a se tornar plena realização se contemplada no horizonte ético da phronesis, pois é aqui que o sujeito age com todas as características necessárias da vida ética, a saber: por uma autodeterminação e controle; por ações deliberada e conscientemente tomadas na seara da liberdade e da compreensão do bem coletivo; por fim, no alcance da felicidade, ascendendo a qualquer estrutura efêmera para fixar-se no bem supremo e fim último e carregado de sentido.

De fato, somente assim cada pessoa entenderá que a justiça não equivale apenas a uma distribuição fortuita mediante méritos e que possa vir a ser corrigida posteriormente. É o processo mais claro para que o juízo elaborado, seja na distribuição de bens e honras, seja na correção que permite a vida social seja, como expressa MacIntyre, segundo "kata ton orhon logon, segundo a reta razão" (MACINTYRE, 2001, p.261)

No horizonte da phronesis, a justiça soergue-se sobre a mera necessidade ou contingências, consegue compreender as determinações peculiares de cada caso, e formatando, objetiva e propositalmente, critérios sobre como bem agir e bem viver, para o bem de outrem, inclusive. A justiça, aqui, não é mera peça retórica nem um conceito vazio: é uma ação, uma obra, que pretende tornar justo tanto quem faz, para quem faz e no que faz. Para tanto, é preciso escolher, deliberar de maneira consciente e racional, em vista não de qualquer coisa, mas da vida em felicidade.

É sem dúvida verdadeiro que o ser humano é o único animal dotado de intelecto.
Mas a capacidade de alguns homens para a atividade intelectual é muito limitada. E
a atividade intelectual não é a única atividade em respeito à qual o ser humano pode
ser dito racional como nenhum outro animal o é (...) Um ser humano se distingue
primordialmente dos animais não por possuir dotes metafísicos naturais, mas sim
pela sua capacidade de planejar sua vida de maneira consciente na busca por um fim
inclusivo (HARDIE, in: ZINGANO, 2010, p. 46)

Rev. de Argumentação e Hermeneutica Jurídica | e-ISSN: 2526-0103 | Porto Alegre | v. 4 | n. 2 | p. 118 - 138 | Jul/Dez. 2018 


\section{CONSIDERAÇÕES FINAIS}

A construção do homem é medida, dentre tantos processos, pela eleição, ou por escolhas. Aquilo que leva alguém ser justo ou não, agir segundo um conjunto de excelências e valores é, antes de um ato, uma escolha. Para ajudar nesse dinamismo exigente, a abertura ao campo da ética e da política são imperativas, o que pressupõe um horizonte mais adequado à natureza humana e àquilo que corresponde ao seu bem.

Por isso que, em Aristóteles, ética e, consequentemente, a vivências dos valores morais, precisam ter sempre uma finalidade. Este fim que vai responder, adequadamente, às questões existenciais mais primitivas e, de certa forma, uma vez que pode fazer isso, ajudar o homem na compreensão de sua vida não como qualquer vida, mas uma vida boa, construída por boas ações. A melhor de todas as ações são aquelas pautadas pela excelência da justiça, cuja natureza de bilateralidade determina a distribuição adequada conforme mérito, a correção do processo distributivo para permitir a igualdade e, por fim, o alcance da equidade, que torna cada um equilibrado para saber lidar com justiça nas mais diversas circunstâncias.

A justiça é a disposição de caráter que torna as pessoas propensas a fazer o que é justo e a desejar o que é justo. Dessa forma, a justiça é uma virtude completa ou é muitas vezes considerada a maior das virtudes. É uma virtude completa por ser o exercício atual da virtude completa, isto é, aquele que a possui pode exercer sua virtude sobre si e sobre o próximo. Por isso se diz que somente a justiça, entre todas as virtudes, é o bem do outro, visto que é possível fazer o que é vantajoso a um outro. O melhor dos homens é aquele que exerce sua virtude para com o outro, pois essa tarefa é a mais difícil.

Além de saber determinar bem o fim, que é o bem de cada coisa, o homem tem que se capacitar para agir sempre em vista deste fim. Isso pressupõe tanto o horizonte da legislação (como critério objetivo das escolhas), quanto à formação de uma disposição de alma que determina o caráter e faz agir, não acidentalmente, mas voluntária e responsavelmente. E isso, segundo Aristóteles, só se dá quando um justo meio é eleito entre os extremos; quando a justiça é exercida, pois por ela, justos são tanto o que a exerce quanto quem a recebe, bem como a própria ação; quando os processos de educação ético-política apontam não só para o bem de si, mas para o bem de todos, na construção da polis.

De fato, a justiça ou qualquer outra excelência em Aristóteles não pode ser tomada como uma ideia ou ideal, mas como uma relação concreta e prática, um fazer individual que

Rev. de Argumentação e Hermeneutica Jurídica | e-ISSN: 2526-0103 | Porto Alegre | v. 4 | n. 2 | p. 118 - 138 | Jul/Dez. 2018 
transborda a esfera privada da moral e recai no comportamento ético junto aos outros convivas, na esfera coletiva da sociedade. A justiça só poderá ser tomada como um elemento eminentemente concreto, relacional, e se permite medir apenas em critérios sociais, na adequação do individual ao todo, no bem particular que se emoldura aos lindes do social.

Pois, como já sabido, em todo pensamento clássico antigo, a ideia de uma ética, de uma agir conforme a excelência e o alcance da phronesis e da sofia só ocorre no âmbito da polis. Não é sem razão que o homem é, segundo Aristóteles, um ser para a vida em comunhão com outros (epeidé fysei politikon ho anthrópos). Assim, a convivência na polis é fundamental para o desenvolvimento da função específico da natureza humana. Onde sucede a mais excelente experiência humana de vida em comunidade há, por evidência, um ser humano mais excelente.

O critério da moralidade para Aristóteles é o justo meio para alcançar um fim racionalmente. O justo meio é o critério para saber o que é a excelência, aprendida pelo hábito, de se treinar na intenção de fazer o Bem, bem para todos. Mas este justo meio presume a capacidade de agir segundo uma sabedoria prática, uma sensatez. Fundamental, portanto, especialmente nas considerações sobre a justiça e bem político, recuperar a noção de phronesis como condutora de uma compreensão aprofundada do agir justo, da práxis e, finalmente, como guia para o alcance da felicidade.

Rev. de Argumentação e Hermeneutica Jurídica | e-ISSN: 2526-0103 | Porto Alegre | v. 4 | n. 2 | p. 118 - 138 | Jul/Dez. 2018 


\section{REFERÊNCIAS BIBLIOGRÁFICAS}

ARISTÓTELES. Ética a Nicômaco. Trad. António de Castro Caeiro. São Paulo: Atlas, 2009.

ARISTÓTELES. Ética a Nicômaco. Tradução, textos adicionais e notas Edson Bini. São Paulo: EDIPRO, 2014. (Série Clássicos Edipro).

AUBEnQUE, Pierre. A Prudência em Aristóteles. 2.ed. Trad. Marisa Lopes. São Paulo: Discurso Editoria; Paulus, 2008.

BARRETTO, Vicente de Paulo (org.). Dicionário de Filosofia do Direito. São Leopoldo: Unisinos, 2006.

BITTAR, Eduardo C. B. A Justiça em Aristóteles. São Paulo: Forense Universitária, 2004.

BITTAR, Eduardo C. B; ALMEIDA, Guilherme de Assis. Curso de Filosofia do Direito. 4.ed. Atlas, 2005. (Atlas Jurídica).

BYWATER, J. Aristotle's Ethica Nicomachea. Oxford: Clarendon Press, 1894. Disponível em http://www.perseus.tufts.edu. Acesso 17 de agosto de 2018.

FERRATER MORA, José. Dicionário de Filosofia. SP: Loyola, 2001. 4 vols.

GUARIGLIA, Osvaldo. La Ética en Aristóteles: o la moral de la virtud. Buenos Aires: Eudeba, 1997.

HUGHES, Gerard J. Aristotle on ethics. London: Routledge, 2001.

JAEGER, Werner. Aristóteles: bases para la historia de su desarollo. Trad. José Gaos. México: Fondo de Cultura Económica, 1994a.

KRAUT, Richard. Aristotle's Ethics. Disponível em http://plato.stanford.edu/entries/aristotle-ethics/. Acesso em 17 de dezembro de 2007.

LIDDELL, Henry George; SCOTT, Robert. An Intermediate Greek-English Lexicon. Oxford: Clarendon Press, 1889.

LIDDELL, Henry George; SCOTT, Robert. A Greek-English Lexicon. Revised and augmented throughout by Sir Henry Stuart Jones with the assistance of Roderick McKenzie. Oxford: Clarendon Press, 1996.

MACINTYRE, Alasdair. Depois da virtude: um estudo em teoria moral. Tradução Jussara Simões. Revisão técnica Helder Buenos Aires de Carvalho. Bauru: EDUSC, 2001.

REALE, Giovanni. Introdução a Aristóteles. Trad. Eliana Aguiar. Rio de Janeiro: Contraponto, 2012. 
ROSS, David. Aristóteles. Trad. Luís Filipe Bragança S. S. Teixeira. Lisboa: Dom Quixote, 1987.

SANDEL, Michael. Justiça: o que é fazer a coisa certa. Trad. Heloísa Matias e Maria Alice Máximo. 6.ed. Rio de Janeiro: Civilização Brasileira, 2012.

VILLEY, Michel. Filosofia do Direito. São Paulo: Martins Fontes, 2005. (Justiça e Direito).

WOLF, Ursula. A Ética a Nicômaco de Aristóteles. Trad. Enio Pualo Giachini. São Paulo: Loyola, 2010.

ZIGANO, Marco. (coord). Sobre a Ética Nicomaqueia de Aristóteles: textos selecionados. São Paulo: Odysseus, 2010.

Rev. de Argumentação e Hermeneutica Jurídica | e-ISSN: 2526-0103 | Porto Alegre | v. 4 | n. 2 | p. 118 - 138 | Jul/Dez. 2018 